\title{
Alzheimer's disease after remote head injury: an incidence study
}

\author{
P W Schofield, M Tang, K Marder, K Bell, G Dooneief, M Chun, M Sano, Y Stern, \\ R Mayeux
}

Gertrude H Sergievsky Center

$M$ Tang

K Marder

Y Stern

R Mayeux

Division of

Epidemiology (School of Public Health)

$R$ Mayeux

Taub Alzheimer's Disease Research Center

$M$ Tang

$\mathrm{R}$ Mayeux

Department of

Neurology

P W Schofield

K Marder

$\mathrm{K}$ Bell

$G$ Dooneief

M Chun

M Sano

Y Stern

R Mayeux

Department of

Psychiatry, Columbia

University, New York

City, USA

R Mayeux

Correspondence to:

Dr R Mayeux, G H

Sergievsky Center, 630 West
168 Sth St, Columbia

University, New York, NY

10032, USA.

Received 2 January 1996

and in final revised form

5 August 1996

Accepted 13 August 1996

\begin{abstract}
Objective-To evaluate a history of remote head injury as a risk factor for subsequent dementia due to Alzheimer's disease.

Methods-271 participants of a community based longitudinal study of aging in north Manhattan without evidence of significant cognitive impairment were interrogated for a history of head injury on two occasions at entry into the study. The examining physician sought a history of head injury with loss of conciousness. Independently, a risk factor interviewer inquired about a history of head injury with loss of consiousness or amnesia, the duration of any loss of consiousness, and the date of the head injury. Patients were followed up with standardised annual evaluations for up to five years to determine the first occurrence of dementia.
\end{abstract}

Results-Over the course of the study incident dementia due to probable or possible Alzheimer's disease was diagnosed in 39 patients. Cox proportional hazards modelling showed that a history of head injury with loss of consiousness reported to the physician was associated with earlier onset of dementia due to Alzheimer's disease (relative risk $(R R)=4 \cdot 1,95 \%$ confidence interval (95\% CI) $1 \cdot 3-12 \cdot 7)$. head injury with loss of consiousness or amnesia reported to the risk factor interviewer was not significantly associated with earlier onset of Alzheimer's disease

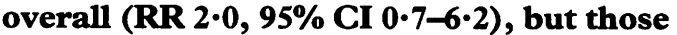
who reported loss of consiousness exceeding five minutes were at significantly increased risk (RR 11.2, 95\% CI 2.3-59.8). Incident Alzheimer's disease was significantly associated with head injury which occurred within the preceding 30 years (RR 5•4, 95\% CI 1·5-19.5).

Conclusion-The results of this cohort study are consistent with the findings of several case-control studies suggesting that head injury may be a risk factor for Alzheimer's disease.

\section{(F Neurol Neurosurg Psychiatry 1997;62:119-124)}

Keywords: Alzheimer's disease; head injury

Head injury with loss of consciousness has been implicated as a possible risk factor for Alzheimer's disease by several case-control studies $^{1-6}$ and by a combined re-analysis of eight previous case-control studies. ${ }^{7}$ Because recall bias is a potential problem with casecontrol studies, the apparent association between remote head injury and dementia may be spurious. Two cohort studies, ${ }^{89}$ in which the history of head injury was obtained before the onset of dementia, failed to confirm an association with subsequent Alzheimer's disease. In this study we investigated the risk for subsequent incident Alzheimer's disease associated with a history of head injury obtained from initially non-demented elderly subjects. Subjects were all participants in a longitudinal, community-based study in the Washington Heights section of Manhattan in New York City.

\section{Methods}

Data were obtained from a community based registry of conditions related to aging in north Manhattan. ${ }^{10}$ To create this registry, nursing homes, home healthcare agencies, private practioners, and hospital admission and discharge lists were canvassed to identify service recipients aged 60 years or more who were invited to take a brief cognitive screening examination $^{11}$ modified from the comprehensive assessment and referral interview. ${ }^{12}$ Almost all subjects entered the study between December 1989 and November 1991. All subjects who screened positive (score $>2$ ) and a randomly selected $26 \%$ of all subjects who screened negative (score $\leqslant 2$ ) were referred to a clinical evaluation team for comprehensive clinical assessments, which were repeated annually. Each annual assessment consisted of a clinical evaluation by a physician (comprising history and general medical and neurological assessments), and a battery of neuropsychological tests administered by a trained tester. The standardised neuropsychological battery consisted of tests of memory (the Buschke selective reminding test ${ }^{13}$ and a multiple choice version of the Benton recognition test ${ }^{14}$ ), orientation, abstract reasoning, ${ }^{15} 16$ language, ${ }^{17} 18$ and construction, ${ }^{19}$ and usually took about an hour to complete. Data from the medical and neuropsychological evaluations, as well as any other laboratory or neuroimaging data that might have been available, were reviewed at a consensus conference which was attended by neurologists directly involved with the clinical evaluation of subjects. At the consensus conference, clinical diagnoses were determined, and a clinical dementia rating score $(C D R)^{20}$ was also assigned. Initial and follow up evaluations 
were performed and reviewed according to the same procedures. Dementia was diagnosed by means of a strict algorithm which required that patients met threshold criteria on neuropsychological evaluation, had evidence of functional impairment either by history or examination, and that the cognitive problems could not be attributed to an acute confusional state. The neuropsychological criteria for dementia were performance below previously defined cut off scores in two out of three memory domains, and in at least two tests of other cognitive domains. ${ }^{10}$ Neuropsychological and functional criteria were also used to define a borderline category for subjects with clinically significant cognitive impairment who failed to meet our criteria for dementia. Most subjects in this category had a CDR of 0.5 . Some subjects with positive screen scores were judged to be free of significant cognitive impairment on the basis of their neuropsychological test performance. NINCDS criteria were used for the diagnoses of probable and possible Alzheimer's disease. ${ }^{21}$

\section{HISTORY OF HEAD INJURY}

A history of head injury was sought from subjects on two separate occasions. The physician probed medical history according to a standardised format which included the question: "have you ever had a head injury with loss of consiousness?" Because subjects were seen in their own homes, clarification and supportive history could be sought from spouses or family members to obtain the best possible information. Independently, a one time risk factor questionaire was conducted with subjects at entry into the study, by trained technicians usually in person. The risk factor questionaire included the question: "have you ever had a head injury with loss of consiousness, or amnesia?" Subjects who endorsed this question were asked when the head injury had occurred, and the duration of any loss of consiousness, which was recorded as either: $<5$ minutes, 5-29 minutes, 29-59 minutes, 1-24 hours, or $>24$ hours. A report of head injury with amnesia but no loss of consiousness, would lead to classification as head injury with loss of consiousness $<5$ minutes by the risk factor interviewer, but that same history would be recorded as no head injury with loss of consiousness by the physician. Because the two independently obtained histories provided different information, each with specific advantages, we performed parallel analyses using both categories of history of head injury. A history of head injury with loss of consiousness reported to the physician we refer to as head injury+PHYS, head injury reported to the risk factor interviewer we refer to as head injury+RF. Physicians also routinely inquired about memory complaints (recorded yes or no).

\section{HISTORY OF ALCOHOL}

Alcohol misuse increases the risk of head injury. ${ }^{22}$ Details of past and present alcohol consumption were obtained at the risk factor interview. We defined a history of problem drinking if any of the following had occurred due to alcohol: the subject had argued, blacked out, been violent, been arrested, been charged with drink driving, lost his job, or missed work. The risk factor questionaire has been found to be reliable on repeated interviews for history of head injury $(\kappa=0.89)$, and for history of alcohol use $(\kappa=0.54) .^{5}$

Apolipoprotein E (APOE) genotype was also known for a subsample of subjects.

\section{ENTRY CRITERIA}

We included all registry subjects who had completed the risk factor interview, and who were neither demented at the initial evaluation, nor in the border zone category of cognitive impairment referred to earlier.

\section{STATISTICAL ANALYSES}

We used $\chi^{2}$ or $t$ tests to evaluate the association between a history of head injury and the cognitive screen score, performance on the Buschke selective reminding test at entry to the study, age, education, sex, frequency of memory complaints, or a history of problem drinking. We performed survival analyses using the Cox proportional hazards model ${ }^{23}$ to assess the age at onset of incident dementia in subjects with and without a history of head injury. The end point chosen for these analyses was the first diagnosis of dementia, or the last visit for those who remained nondemented. Similar Cox analyses were performed to assess the importance of severity of head injury for risk of Alzheimer's disease. In these analyses subjects were grouped according to severity of head injury, and the group specific risk estimates for incident Alzheimer's disease were obtained relative to the referent group comprising all subjects without head injury. We assessed the effect of latency of head injury in similar fashion, in which latency was defined as the time between head injury and diagnosis of dementia, or between head injury and final visit for subjects who remained non-demented. Previous studies have found latencies $<10$ years, $^{34}$ or $<30$ years $^{3}$ to be associated with increased risk for Alzheimer's disease. We therefore classified subjects with previous head injury into groups based on these latencies $(<10$ years, $\geqslant 10$ years, and also $<30$ years, $\geqslant 30$ years) and undertook Cox analyses to obtain risk estimates for these groups compared with the referent group of subjects without head injury. In all Cox analyses we adjusted for sex and education and stratified by age at entry into the study (age $<70,70-80,80+)$.

\section{Results}

Two hundred and seventy one subjects satisfied entry criteria. Subjects were followed up from $0-5$ years, with a mean duration of follow up of 20.5 months. Twenty seven subjects reported head injury+RF and 19 subjects reported head injury+PHYS. Sixty one (26\%) subjects without any history of head injury were lost to follow up after the initial evaluation as were four $(21 \%)$ head injury+PHYS 
Table 1 Comparison of risk factor interviewer and physician history of head injury

\begin{tabular}{llc}
\hline & \multicolumn{2}{l}{$\begin{array}{l}\text { Risk factor form history } \\
\text { History of head injury with LOC or amnesia? }\end{array}$} \\
\cline { 2 - 3 } Physician history & Yes & No \\
\hline History of head injury with LOC & 14 & 5 \\
Yes (n) & $3(21)$ & $1(20)$ \\
Yes and AD on follow up (n(\%)) & 13 & $239^{\star}$ \\
No (n) & $1(8)$ & $34(14)$ \\
No and AD on follow up (n(\%)) & $1(8)$
\end{tabular}

*Includes three subjects who denied head injury at risk factor interview for whom no response was recorded to head injury question in physicians' history.

LOC = loss of consiousness; $A D=$ probable or possible Alzheimer's disease.

and six (22\%) head injury+RF subjects. These subjects díd not differ for age, education, or baseline total recall compared with those with follow up. Data on head injury were missing from the physician interview for three subjects, all of whom denied head injury at the risk factor interview. To obtain the most conservative estimates of the association between head injury+PHYS and Alzheimer's disease we assumed all three lacked a history of head injury, and included them in all analyses. A history of head injury was obtained by both the physician and risk factor interviewer from 14 subjects, by the physician only from five subjects, and by the risk factor interviewer only from 13 subjects (table 1 ). We attempted to contact all 18 subjects for whom the risk factor and physician interviews were incongruent. We suceeded in reinterviewing only six subjects, none of whom had been demented when last formally assessed. A history of head injury with loss of consiousness was confirmed in three, was denied in two, and remained uncertain in one instance. Reclassification of the two subjects who denied head injury strengthened the association between head injury and Alzheimer's disease and we therefore included all subjects in our analyses according to their initial classification. Table 2 presents subject characteristics. Subjects with head injury+PHYS were younger at entry to the study, but there were no other significant differences between subjects with and without head injury, whether recorded by the physician or the risk factor interviewer.

Table 2 Subject characteristics: 14 subjects are included in both $H I+R F$ and $H I+P H Y S$ categories

\begin{tabular}{|c|c|c|c|c|}
\hline & $\begin{array}{l}\text { No HIt } \\
(n=239)\end{array}$ & $\begin{array}{l}H I+R F \ddagger \\
(n=27)\end{array}$ & $\begin{array}{l}H I+P H Y S S \\
(n=19)\end{array}$ & $\begin{array}{l}\text { Total } \\
(n=271)\end{array}$ \\
\hline $\begin{array}{l}\text { Sex } \\
\text { Female }(\mathrm{n}(\%))\end{array}$ & $177(74)$ & $16(60)$ & $11(58)$ & $197(73)$ \\
\hline Age at entry (y) (mean (SD)) & $75 \cdot 6(7 \cdot 4)$ & $73 \cdot 9(7 \cdot 2)$ & $71 \cdot 2(6 \cdot 5)^{\star}$ & $75 \cdot 3(7 \cdot 3)$ \\
\hline Education (y) (mean (SD)) & $8 \cdot 0(4 \cdot 1)$ & $8 \cdot 2(3.8)$ & $8.8(3.4)$ & $8 \cdot 0(4 \cdot 1)$ \\
\hline Baseline total recall (mean (SD)) & $36.9(8 \cdot 3)$ & $37 \cdot 9(7 \cdot 8)$ & $38 \cdot 0(8 \cdot 5)$ & $37 \cdot 0(8 \cdot 3)$ \\
\hline Cognitive screen score (mean (SD)) & $2 \cdot 6(2 \cdot 5)$ & $2 \cdot 5(2 \cdot 3)$ & $3 \cdot 0(3 \cdot 0)$ & $2 \cdot 6(2 \cdot 6)$ \\
\hline History of problem drinking (n(\%)) & $\begin{array}{l}84(33) \\
10(4)\end{array}$ & $\begin{array}{c}11(41) \\
2(7)\end{array}$ & $\begin{array}{l}7(37) \\
2(10)\end{array}$ & $\begin{array}{l}96(35) \\
14(5)\end{array}$ \\
\hline $\begin{array}{l}\text { Duration of follow up (months) } \\
\text { (mean (SD)) }\end{array}$ & $20 \cdot 7(15 \cdot 7)$ & $20 \cdot 2(13 \cdot 8)$ & $22 \cdot 8(15 \cdot 5)$ & $20 \cdot 5(15 \cdot 5)$ \\
\hline $\begin{array}{l}\text { Any dementia at follow up (n(\%)) } \\
\mathrm{AD} \text { at follow up }(\mathrm{n}(\%))\end{array}$ & $\begin{array}{l}41(17) \\
34(14)\end{array}$ & $\begin{array}{l}6(22) \\
4(15)\end{array}$ & $\begin{array}{l}5(26) \\
4(21)\end{array}$ & $\begin{array}{l}48(18) \\
39(14)\end{array}$ \\
\hline $\begin{array}{l}\text { Age at } \mathrm{AD}(\mathrm{y}) \text { diagnosis }(\mathrm{y}) \\
(\text { mean }(\mathrm{SD}))\end{array}$ & $82 \cdot 8(7 \cdot 9)$ & $80 \cdot 0(9 \cdot 8)$ & $75 \cdot 0(10 \cdot 0)$ & $82 \cdot 0(8 \cdot 2)$ \\
\hline
\end{tabular}

†No history of head injury to either physician or risk factor interviewer, includes three subjects with no history recorded by physician, who denied history of head injury to risk factor interviewer.

$\ddagger$ History of head injury obtained by risk factor interview.

SHistory of head injury obtained by physician.

Total recall score from the Buschke selective reminding test.

$\mathrm{HI}=$ history of head injury; $\mathrm{AD}=$ probable or possible Alzheimer's disease; $\mathrm{RF}=$ risk factor

interviewer; $\mathrm{PHYS}=$ physician

${ }_{\star} p<0.05 ; \pm$ test $v$ comparison group with no head injury.
INCIDENT DEMENTIA

Incident dementia was found in 48 subjects. Aetiological diagnoses included probable and possible Alzheimer's disease $(\mathbf{n}=39)$, dementia associated with Parkinson's disease $(n=2)$, and other dementias $(n=7)$. Alzheimer's disease was diagnosed in three subjects with head injury by both histories, in one subject with head injury by physician's history alone, and in one subject with head injury by risk factor interview alone (table 1)

In Cox's proportional hazards model analyses, the RR for incident dementia due to any cause associated with head injury+ PHYS was $3 \cdot 2$ (95\% CI 1.2-8.6); with head injury+ risk factor the RR was $2 \cdot 1(95 \% \mathrm{CI} 0 \cdot 8-5 \cdot 3)$.

To investigate the association between head injury and Alzheimer's disease, we excluded the nine subjects with non-Alzheimer's disease dementia, and repeated the analyses. Head injury+ PHYS was associated with significant risk for dementia (RR 4.1, 95\% CI 1·3-12.7), but the risk associated with head injury $+\mathrm{RF}$ was not significant (RR $2 \cdot 0,95 \%$ CI $0 \cdot 7-6 \cdot 2$ ). To determine if risk differed within strata defined by cognitive screen score, we conducted separate Cox analyses for subjects with acognitive screen score $\leqslant 2$ (low score), and for those who scored $>2$ (high score). Similar point estimates of risk associated with head injury+PHYS were obtained within the low score (OR 6.0) and high score (OR 3.9) groups. Risk estimates for Alzheimer's disease associated with head injury+RF were also similar in the low score (OR 3.6) and high score groups (OR 2.5). Furthermore, Cox models which included the cognitive screen score group (high or low) as a dichotomous independent variable did not alter the risk estimates associated with history of head injury. In another Cox model, covariates included sex; education; the total recall score of the Buscke selective reminding test at baseline as a continuous variable to adjust for initial cognitive performance; memory complaints as a dichotomous variable (yes or no); in addition to history of head injury. In these models the risk estimates associated with head injury+ PHYS (RR 3.6, 95\% CI $1 \cdot 2-11 \cdot 2$ ) or head injury+RF ( $R R \quad 1 \cdot 9,95 \%$ CI $0 \cdot 6-5 \cdot 8$ ) were similar to previous estimates. Finally, we assessed head injury in this last Cox model redefined as a positive history of head injury to both physician and risk factor interviewer. Head injury defined in this way was also associated with increased risk for incident Alzheimer's disease, although it missed the level of significance ( $R R$ 3.1, 95\% CI $0 \cdot 9-10 \cdot 8)$.

\section{SEVERITY OF HEAD INJURY AND LATENCY TO} DEMENTIA

Eighteen subjects reported the duration of their loss of consiousness to the risk factor interviewer and this was used as a dichotomised index of severity of head injury: loss of consiousness < five minutes $(n=12)$, and loss of consiousness $\geqslant$ five minutes ( $n=$ 6). In Cox analyses, loss of consiousness $\geqslant$ five minutes was associated with significantly 
increased risk for Alzheimer's disease ( $R R$ $11 \cdot 2,95 \%$ CI $2 \cdot 3-59 \cdot 8)$; whereas loss of consiousness < five minutes was not (RR $1 \cdot 7$, $95 \%$ CI 0.4-7.5).

The mean latency in four subjects with incident Alzheimer's disease was 14.5 (SD 15.3) years, and in the 14 who reported their age at head injury and remained non-demented, the mean latency was 35.5 (SD 26.2) years. Head injury with latency $<30$ years was significantly associated with Alzheimer's disease (RR 5.4, 95\% CI 1.5-19.5), whereas more remote head injury was not (RR $1 \cdot 7,95 \%$ CI $0 \cdot 2-14 \cdot 4)$. In a separate analysis, head injury with latency $<10$ years (RR $4.5,95 \%$ CI $1.0-21.0$ ) and with $\geqslant 10$ years (RR $3 \cdot 0,95 \%$ CI $0 \cdot 7-14 \cdot 2$ ) were both associated with point estimates of increased risk.

We repeated our analyses, adjusting for APOE status, known for only 125 subjects, including 11 head injury+PHYS and 14 head injury+RF subjects. In these analyses, the point estimates of risk associated with head injury+PHYS (OR $3 \cdot 1,97 \%$ CI $0 \cdot 8-12 \cdot 5$ ), and head injury+RF (OR $2.3,95 \%$ CI 0.5-10.0) remained raised. Only one head injury+PHYS and two head injury+RF subjects were APOE $\varepsilon 4+$, none of whom became demented.

\section{Discussion}

Our results indicate that head injury may be associated with an earlier age at onset of Alzheimer's disease, and are consistent with the results of several previous case-control studies, ${ }^{1-6}$ which suggest that a history of head injury with loss of consiousness may be a significant risk factor for Alzheimer's disease.

The discordance in the history of head injury obtained by the physician and that obtained by the risk factor interviewer has several possible explanations. Because the risk factor question was more inclusive and led to more reports of head injury, more mild head injury may have been recorded by the risk factor interviewers. In addition, some subjects may have had variable recall of head injury, although the high consistency we previously demonstrated for response to the risk factor for head injury question suggested that it probably occurred very infrequently. ${ }^{5}$ No independent source of the history of head injury was sought, such as hospital or doctors' records, because of the associated practical difficulties and the potential bias introduced by excluding injuries which did not have medical attention.

Errors of recall or misclassification of history of head injury would only have been critical for our study if they arose differentially. Although we obtained the history of head injury from subjects who were all initially cognitively intact to avoid the obvious potential for recall bias inherent in case-control studies of Alzheimer's disease, some potential for recall bias still existed. Subjects with memory complaints-typically for recent rather than distant events and perhaps reflecting the earliest manifestations of preclinical Alzheimer's dis- ease-might have been more likely to recall a past head injury in an effort to account for their symptoms. However, we found no association between memory complaints and history of head injury, and the association between head injury and subsequent Alzheimer's disease was not significantly modified by the addition of memory complaints to the Cox model analyses. Thus although there may have been some errors with respect to the history of head injury, we have no evidence to suspect a bias in the frequency of errors that may have been related to the outcome.

Our results contrast with those of two previous cohort studies which failed to identify an association between head injury and subsequent dementia. In the study by Williams et $a l,{ }^{8} 821$ subjects without evidence of the target illnesses before their head injury, who were older than 40 years when most recently evaluated, were followed up by medical linkage retrieval over 15000 person-years for the development of dementia and other degenerative diseases. The standardised morbidity for dementia in this study population, due to dementia and to Alzheimer's disease specifically, was no different from that in a control population. Latency from head injury to onset of dementia was not significant; nor was there any significant effect of severity of head injury for the risk of subsequent dementia. In a prospective cohort study, Katzman et al followed up 434 volunteers who at intake were "ambulatory, functional, presumably nondemented, and between 75 and 85 years of age." Fifty six subjects became demented, and head injury did not seem to be a risk factor. A prior history of head injury was reported in $3.1 \%$ and $20 \%$ of subjects with postintake diagnoses of Alzheimer's disease and multiinfarct dementia/mixed dementia, and in $10 \%$ of those who remained without cognitive impairment at the end of the study. Neither severity nor latency effects were evaluated in that study. There are several methodological differences between these studies and ours, which may in part account for the different results. In the study by Williams et al, dementia was diagnosed by the subjects' own physicians; subjects with onset of dementia as young as 40 were eligible for inclusion, and standardisation of estimates of dementia onset may have been difficult. By contrast, our subjects were older than 60 at their initial evaluation, (almost all were older than 65). Because they were evaluated annually we were able to establish the age at onset of dementia using uniform diagnostic criteria, based on detailed neuropsychological testing. In the study by Katzman et al, subjects were on average older than our subjects. In addition they were volunteers, by contrast with most of our subjects who were approached with a request to participate in the study.

There are several possible mechanisms by which head injury might increase the risk for Alzheimer's disease. Head injury might cause cerebral damage and thereby lower the reserve against the cognitive consequences of subsequent, entirely unrelated cerebral pathology, 
including Alzheimer's disease. ${ }^{24}$ There are few human pathological data concerning the cerebral consequences of mild to moderate head injury-necropsy studies are limited to a few reports of individuals who died from causes not directly related to the head injury. ${ }^{25} 26 \mathrm{On}$ the other hand, several large follow up studies of victims with mild head injury indicate that neuropsychological abnormalities may persist for weeks or even months after injury ${ }^{27-29}$ and recovery from the cognitive effects of head injury seems even more delayed in those with a history of previous head injury. ${ }^{30}$ Evoked potential abnormalities are detected in a high proportion of victims of head injury, persisting in some cases for more than six weeks. ${ }^{31}$ These results are consistent with the possibility that mild to moderate head injury causes structural brain changes in some subjects. At least two predictions follow from the "loss of reserve" theory, as far as population studies of head injury and subsequent Alzheimer's disease are concerned. Head injury should be associated with a younger age at onset of dementia; and more severe head injury should be associated with greater risk for Alzheimer's disease, as it is likely to be associated with more brain damage. The findings in our study were consistent with both these predictions. Gedye et al also reported that head injury was associated with a younger age of onset of Alzheimer's disease. ${ }^{32}$ A positive association between increasing severity of head injury and increasing risk for Alzheimer's disease has been found in a previous study. ${ }^{5}$

A second possible mechanism is that head injury might be particularly damaging when it occurs during the presymptomatic phase of Alzheimer's disease. The duration of the presymptomatic period in Alzheimer's disease is unknown, but pathological studies of subjects with Down's syndrome-in whom Alzheimer's disease-like changes develop with some predictability - suggest that it might well exceed 10 years, ${ }^{33-35}$ and a recent clinical study indicated that subtle cognitive changes may precede clinical dementia by at least seven years. ${ }^{36}$ The brains of normal animals subjected to mild head injury show characteristic cytoskeletal abnormalities very soon after injury, but there is subsequent repair. ${ }^{37-40}$ If the capacity for repair was diminished in presymptomatic Alzheimer's disease, even mild head injury might add to the neuropathological burden leading to earlier diagnosis of the underlying Alzheimer's disease. Conversely, if head injury accelerated the progression of Alzheimer's disease pathology in those with presymptomatic disease, earlier clinical onset would also arise, consistent with the findings of this study. The APOE $\varepsilon 4$ allele may be associated with less effective CNS repair after injury. ${ }^{41}$ The results of a recent case-control study in which head injury was a risk factor for Alzheimer's disease only among subjects with APOE $\varepsilon 4$ would be consistent with the hypothetical mechanisms considered above. ${ }^{6}$ In the current study, too few subjects with APOE $\varepsilon 4$ reported head injury for us to seek an interaction between APOE $\varepsilon 4$ and head injury, but our results did suggest that the presence of APOE $\& 4$ may not be necessary for the association between head injury and earlier onset of Alzheimer's disease.

A third possible mechanism for the association between head injury and Alzheimer's disease is that head injury might function as a catalyst, to trigger or promote some critical early event in the pathogenesis of Alzheimer's disease. Several reported cases of early onset Alzheimer's disease which presented after head injury suggest such a possibility. ${ }^{42-44}$ Recent studies by Roberts et al indicate that, with severe head injury at least, upregulation of amyloid precursor protein processing may occur. ${ }^{45}$ As abberant amyloid processing or excessive amyloid production are proposed by some to be central early events in Alzheimer's disease pathogenesis, ${ }^{46}$ this finding suggests a mechanism by which head injury might play a part in causation of Alzheimer's disease.

There were some limitations to our study. Laboratory evaluations were not routinely available for all subjects, and this may have led to diagnostic errors with respect to the aetiology of the dementia in some cases. Relatively few subjects gave a history of head injury, and the $95 \%$ CIs for the association between head injury and Alzheimer's disease were wide, particularly when we stratified analyses to assess the importance of severity and latency of head injury. Larger prospective studies with greater statistical power will clearly be important to re-evaluate this question. Our study also has strengths. The cohort design significantly reduced the likelihood of recall bias with respect to history of head injury. A history of head injury was sought twice, and we identified incident cases of dementia by uniform criteria derived mainly from the results of comprehensive neuropsychological evaluations. Estimates of severity of head injury were available, by contrast with many previous case control studies.

In summary, our findings offer further support for an association between head injury and Alzheimer's disease. This association could arise if head injury shortened the long preclinical period of Alzheimer's disease, or if head injury had a direct role in initiating the disease.

We thank Dr Wei-Yann Tsai in the Biostatistics department, School of Public Health, Columbia University, for his review of the statistical analyses.

This work was supported by federal grants AG07232, AG 10963, AG08702, and RR00645 and from the Charles S Robertson Memorial Gift for Alzheimer's Disease Research from the Banbury Fund.

1 Heyman A, Wilkinson WE, Stafford JA, Helms MJ, Sigmon AH, Weinberg T. Alzheimer's disease: a study of epidemiological aspects. Ann Neurol 1984;15:335-41.

2 Mortimer JA, French LR, Hutton JT, Schuman LM. Head injury as a risk factor for Alzheimer's disease Neurology 1985;35:264-7.

3 Graves AB, White E, Koepsell TD, et al. The association between head trauma and Alzheimer's disease. $A m$ Epidemiol 1990;131:491-501.

4 Van Duijn CM, Tanja TA, Haaxma R, et al. Head trauma and the risk of Alzheimer's disease. Am 7 Epidemiol 1992;135:775-82.

5 Mayeux R, Ottman R, Ming-Xin Tang, et al. Genetic susceptibility and head injury as risk factors for Alzheimer's disease among community-dwelling elderly persons and their first-degree relatives. Ann Neurol 1993;33:494-501.

6 Mayeux R, Ottman R, Maestre G, et al. Synergistic effects of head injury and apolipoprotein e4 in Alzheimer's disease: 
a link between divergent hypotheses? Neurology 1995;45: 555-7.

7 Mortimer JA, Van Duijn CM, Chandra V, et al. Head trauma as a risk factor for Alzheimer's disease: a collaborative re-analysis of case-control studies Int 7 Epidemiol 1991;20:S28-S35.

8 Williams DB, Annegers JF, Kokmen E, O'Brien PC, Kurland LT. Brain injury and neurologic sequelae: a cohort study of dementia, parkinsonism, and amyotrophic lateral sclerosis. Neurology 1991;41:1554-7.

9 Katzman $\mathrm{R}$, Aronson $\mathrm{M}$, Fuld $\mathrm{P}$, et al. Development of dementing illnesses in an 80-year-old volunteer cohort. dementing illnesses in an $80-y$
Ann Neurol 1989;25:317-24.

10 Stern Y, Andrews H, Pittman J, et al. Diagnosis of dementia in a heterogeeous population: development of a neuropsychological paradigm-based diagnosis of dementia and quantified correction for the effects of education Arch Neurol 1992;49:453-60.

11 Wilder D, Cross P, Chen J, et al. Operating characteristics of brief screens for dementia in a multicultural population. Am f Geriatr Psychiatry 1995;3:96-107.

12 Gurland B, Wilder D. The "CARE" interview revisited: development of an efficient, systematic, clinical assessment. 7 Gerontol 1984;39:129-37.

13 Buscke $\mathrm{H}$, Fuld PA. Evaluating storage, retention, and retrieval in disordered memory and learning. Neurology $1974 ; 24: 1019-25$.

14 Benton AL. The visual retention test. New York: The Psychological Corporation, 1955

15 Wechsler D. Wechsler adult intelligence scale-revised. New York: The Psychological Corporation, 1981.

16 Mattis S. Mental Status examination for organic mental syndrome in the elderly patient. In: Bellak L, Karasu TB eds. Geriatric psychiatry, New York: Grune and Stratton, 1976.

17 Kaplan E, Goodglass H, Weintraub S. Boston naming test. Philadelphia: Lea and Febiger, 1983

18 Goodglass H, Kaplan D. The assessment of aphasia and related disorders. 2nd ed. Philadelphia: Lea and Febiger, 1981

19 Rosen W. The Rosen drawing test. Bronx, New York: Veterans Administration Medical Center, 1981.

20 Burke WJ, Miller JP, Rubin EH, et al. The reliability of the Washington University clinical dementia rating. Arch Neurol 1988;45:31-2.

21 McKhann G, Drachman D, Folstein M, Katzman R, Price $\mathrm{D}$, Stadlan EM. Clinical diagnosis of Alzheimer's disease: report of the NINCDS-ADRDA Work Group under the auspices of Department of Health and Human Services Task Force on Alzheimer's disease. Neurology 1984;34:939-44.

22 Galbraith S, Murray WR, Patel AR, et al. The relationship between alcohol and head injury and its effect on the conscious level. Br F Surg 1976;63:128-30.

23 Lawless JF. Statistical model and methods for lifetime data. New York: Wiley and Sons, 1982.

24 Mortimer JA, Pirozzolo FJ. Remote effects of head trauma Dev Neuropsychol 1985;1:215-29.

25 Oppenheimer DR Microscopic lesions in the brain following head injury. $f$ Neurol Neurosurg Psychiatry 1968;31: 299-306.

26 Hume Adams J, Doyle D, et al. Diffuse axonal injury in head injury: definition, diagnosis and grading. Histopathology 1989;15:49-59.
27 Gronwall D, Wrightson P. Delayed recovery of intellectual fuction after minor head injury. Lancet 1974;ii:605-9.

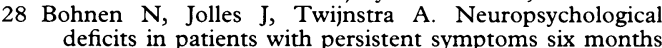
after mild head injury. Neurosurgery 1992;30:692-6.

29 Barth JT, Macciocchi SN, Giordani B, Rimel R, Jane JA, Boll TJ. Neuropsychological sequelae of minor head injury. Neurosurgery 1983;13:529-33.

30 Gronwall D, Wrightson P. Cumulative effect of concussion. Lancet $1975 ; \mathbf{i i}: 995-7$.

31 Montgomery EA, Fenton GW, McClelland RJ, MacFlynn $\mathrm{G}$, Rutherford WH. The psychobiology of minor head injury. Psychol Med 1991;21:375-84.

32 Gedye A Beattie BL, Tuokko H, Horton A, Korsarek E. Severe head injury hastens age of onset of Alzheimer's disease. F Am Geriatr Soc 1989;37:970-3.

33 Whalley LJ. The dementia of Down's syndrome and its relevance to aetiological studies of Alzheimer's disease. Ann NY Acad Sci 1982;396:39-53.

34 Thase ME, Tigner R, Smelzer DJ, Liss L. Age-related neuropsychological deficits in Down's syndrome. Biol Psychiatry 1984;19:571-85.

35 Lai F, Williams RS. A prospective study of Alzheimer's disease in Down syndrome. Arch Neurol 1989;46: 849-53.

36 Linn RT, Wolf PA, Bachman DL, et al. The "preclinical phase" of probable Alzheimer's disease: a 13-year prospective study of the Framingham cohort. Arch Neurol 1995;52:485-90.

37 Povlishock JT, Becker DP, Cheng CLY, Vaughan GW. Axonal change in minor head injury. $\mathcal{F}$ Neuropathol Exp Neurol 1983;42:225-42.

38 Povlishock JT, Erb DE, Astruc J. Axonal response to traumatic brain injury: reactive axonal change, deafferentation, neuroplasticity. $\mathcal{F}$ Neurotrauma 1992;9: S189-200.

39 Povlishock JT. Traumatically induced axonal injury: pathogesis and pathobiological implications. Brain Pathol 1992;2:1-12.

40 Erb DE, Povlishock JT. Neuroplasticity following traumatic brain injury: a study of GABAergic terminal loss and recovery in the cat dorsal lateral vestibular nucleus. and recovery in the cat dorsal

41 Poirier J. Apolipoprotein E in animal models of CNS injury and in Alzheimer's disease. Trends Neurosci 1994;17: and in

42 Rudelli R, Strom JO, Welch PT, Ambler MW. Posttraumatic premature Alzheimer's disease: neuropathologic findings and pathogenetic considerations. Arch Neurol 1982;39:570-5

43 Corsellis JAN, Brierly JB. Observations on the pathology of insidious dementia following head injury. 7 Ment $S_{c}$ 1959;105:714-20.

44 Claude H, Cuel J. Démence pré-sénile post-traumatique aprés fracture du créne: considérations medico-légales. Ann Med Leg 1939;19:173-84.

45 Roberts GW, Gentleman SM, Lynch A, Murray L, Landon M, Graham DI. Beta amyloid protein deposition in the brain after severe head injury: implications for the pathobrain after severe head injury: implications for the patho-
genesis of Alzheimer's disease. $尹$ Neurol Neurosurg genesis of Alzheimer's
Psychiatry 1994;57:419-25.

46 Selkoe DJ. Physiological production of the Beta-amyloid protein and the mechanism of Alzheimer's disease. Trends Neurosci 1993;16:403-9. 